\title{
Penataan Trayek Angkutan Perkotaan Di Kabupaten Paser
}

\author{
${ }^{1}$ Intan Novianingsih, ${ }^{2}$ Defin Nur Wahdani, ${ }^{3}$ Dani Hardianto \\ ${ }^{1}$ Kementerian Perhubungan Republik Indonesia \\ ${ }^{2}$ Kementerian Perhubungan Republik Indonesia \\ ${ }^{3}$ Politeknik Transportasi Darat Indonesia-STTD \\ Email: intan.novianingsih@dephub.go.id
}

\begin{abstract}
Abstrak
Sistim transportasi umum merupakan unsur penting dalam pengembangan suatu wilayah. Angkutan umum harus memberikan layanan terbaik agar dapat berperan serta menunjang aksesibilitas masyarakat. Disamping itu peran stakeholder seperti pemerintah sangat dibutuhkan dalam perencanaan dan penataan trayek dengan memperhatikan tata guna lahan dan permintaan dari pengguna jasa. Oleh karena itu tujuan penelitian ini mengangkat tentang penataan trayek angkutan perkotaan di Kabupaten Paser. Desain penelitian ini meliputi pengumpulan data, evaluasi kinerja angkutan umum, indentifkasi permasalahan, pengolahan data dan evaluasi. Hasil penelitian menunjukkan kinerja trayek eksisting belum memenuhi standar yang telah ditetapkan, beberapa indikator bahkan tidak bisa dilakukan penilaian karena belum ada asal dan tujuan yang tetap. Hasil dari penataan, diperoleh angkutan perkotaan yang semula satu trayek menjadi tiga trayek.
\end{abstract}

Kata Kunci: Penataan Trayek, Transportasi, Angkutan Umum, Penumpang.

\begin{abstract}
The public transportation system is an important element in the development of a region. Public transport must provide the best service in order to participate and support community accessibility. In addition, the role of stakeholders such as the government is needed in planning and structuring routes by paying attention to land use and requests from service users. Therefore, the purpose of this study is to raise the arrangement of urban transportation routes in Paser Regency. The design of this research includes data collection, evaluation of public transport performance, identification of problems, data processing and evaluation. Research results hows that the performance of the existing route does not meet the standards that have been set, some indicators cannot even be assessed because there is no fixed origin and destination. The results of the arrangement, obtained urban transportation which was originally one route to three routes.
\end{abstract}

Keywords: Route Arrangement, Transportation, Public Transportation, Passenger

\section{A. PENDAHULUAN}

Sistem transportasi angkutan umum merupakan unsur penting dalam mengembangkan dan memajukan suatu wilayah, terkait dengan fungsi transportasi yaitu fungsi pelayanan dan fungsi perintis (ship follow the trade and trade follow the ship). Angkutan umum berperan menunjang aksesibilitas masyarakat dalam melakukan perpindahan, pelayanan angkutan umum diharapkan mampu menyediakan aksesibilitas yang baik bagi penggunanya. Oleh karena itu perencanaan trayek angkutan umum harus memperhatikan tata guna lahan (land use) dan potensi permintaan (demand) dari pengguna jasa. Dengan terciptanya pelayanan angkutan umum yang handal diharapkan dapat mengurangi penggunaan bahan bakar, biaya perjalanan, dan kemacetan dikarenakan beban pada jalan dapat diminimalisir dibanding dengan penggunaan kendaraan pribadi sebagai mobilitasnya.

Transportasi adalah pemindahan manusia atau barang dari suatu tempat ke tempat lainnya dalam waktu tertentu dengan menggunakan sebuah kendaraan yang digerakkan oleh manusia, 
hewan, maupun mesin. Morlok (1987), mendefinisikan transportasi adalah kegiatan memindahkan atau mengangkut dari suatu tempat ke tempat lain; Menurut Soejono (1990), mengatakan bahwa transportasi dapat diartikan sebagai kegiatan yang memungkinkan perpindahan manusia dan atau barang dari satu tempat ke tempat lainnya. Sementara Warpani (2002), transportasi atau perangkutan adalah kegiatan perpindahan orang dan barang dari satu tempat (asal) ke tempat lain (tujuan) dengan mendukung aktivitas manusia.

Permintaan jasa transportasi sebagai permintaan turunan (derived demand) yang timbul adanya permintaan akan komoditas atau jasa lainnya. Dengan demikian permintaan transportasi baru akan ada apabila terdapat faktor-faktor pendorongnya (Morlok, 2004).

a. Kelompok Choice. Pilihan seseorang untuk menentukan moda yang digunakan dalam melakukan mobilitas. Sehingga tidak ada kata terpaksa dalam menggunakan angkutan umum. Kelompok ini bisa saja menggunakan kendaraan pribadi, dengan alasan legal, finansial, dan fisik.

b. Kelompok Captive. Kelompok ini terdiri dari orang-orang yang tidak mempunyai pilihan lain selain menggunakan angkutan umum dalam melakukan mobilitas. Hal ini dikarenakan tidak dapat menggunakan kendaraan pribadi.

Semakin banyak kelompok choice, maka negara tersebut semakin maju. Hal ini dikarenakan, walaupun kelompok choice memiliki kendaraan pribadi, penggunaan angkutan umum tetap menjadi prioritas utama. Sebaliknya, bila semakin banyak kelompok captive, maka negara tersebut dapat dikategorikan sebagai negara yang masih berkembang. Hal ini dikarenakan kondisi perekonomiannya yang masih kurang.

Menurut Warpani (2002), angkutan umum adalah angkutan yang digunakan oleh umum dan dilaksanakan dengan dipungut bayaran. Sementara trayek adalah lintasan kendaraan motor umum untuk pelayanan jasa angkutan orang dengan mobil penumpang atau mobil bus yang mempunyai asal dan tujuan perjalanan tetap, dan jenis kendaraan tetap serta berjadwal atau tidak berjadwal. Rute angkutan umum yang baik adalah mengikuti pola pergerakan penumpang angkutan sehingga tercipta pergerakan yang lebih efesien. Trayek angkutan umum harus dirancang sesuai dengan pola pergerakan penduduk, sehingga transfer moda pada saat penumpang mengadakan perjalanan dengan angkutan umum dapat diminimumkan.

Berdasarkan SK trayek No 551 / SK.427 / 1997 Tentang Penetapan Jaringan Trayek Dalam Daerah Kabupaten Daerah Tingkat II Paser terdapat satu trayek angkutan perkotaan dengan jumlah armada yang diizinkan sebanyak 18 armada namun dengan jumlah tersebut yang beroperasi hanya 15 armada. Minimnya ketersediaan armada dengan wilayah perkotaan yang berada di Kecamatan Tanah Grogot seluas 335,58 km2 dengan jumlah penduduk 6.454 jiwa seharusnya memiliki cakupan pelayanan yang tinggi namun kondisi saat ini justru angkutan perkotaan tidak berjalan sebagaimana mestinya dimana angkutan perkotaan tidak memiliki rute yang tetap dan masih adanya daerah yang belum dapat terlayani secara maksimal. Hal tersebut juga mengakibatkan pihak yang terkait mengalami kerugian yakni pemerintah akan mengalami kesulitan dalam pengawasan dan penggunaan terminal sebagai titik awal dan akhir perjalanan, operator akan mengalami kesulitan dalam pembiayaan operasi kendaraannya karena rendahnya pendapatan, serta merangsang masyarakat untuk tetap menggunakan kendaraan pribadi khususnya sepeda motor yang memiliki persentase tertinggi sebesar $81 \%$ dibanding penggunaan angkutan umum yang hanya $1 \%$ sebagai akibat dari kurang memadainya pelayanan angkutan umum. Kondisi lalu lintas di Kabupaten Paser belum menunjukkan permasalahan yang signifikan, volume lalu lintas pada ruas jalan dengan $\mathrm{V} / \mathrm{C}$ ratio terbesar hanya $0,31 \mathrm{smp} / \mathrm{jam}$, tetapi untuk menunjang aksesibilitas dan 
menekan penggunaan kendaraan pribadi, angkutan perkotaan sangat diperlukan karena dapat menunjang mobilitas secara massal sehingga penggunaan ruang lalu lintas dapat lebih efisien.

Dari kondisi angkutan perkotaan di Kabupaten Paser perlu dilakukan pengkajian lebih lanjut untuk mendapatkan unjuk kerja pelayanan angkutan perkotaan agar terjadi keseimbangan terhadap permintaan jasa transportasi dengan jasa yang ditawarkan.

\section{B. METODE}

Alur pikir penelitian disusun dengan memperhatikan jenis data yang diperlukan berkaitan dengan objek yang akan diteliti. Data-data tersebut berupa data primer dan data sekunder yang diperoleh dari hasil pengamatan di lapangan maupun instansi terkait, selanjutnya data tersebut diproses mulai dari meng-input sampai didapatkan output-nya melalui analisis dengan metodemetode yang dapat diterima secara ilmiah. Desain penelitian ini meliputi pengumpulan data, evaluasi kinerja angkutan umum, indentifkasi permasalahan, pengolahan data dan evaluasi.

\section{HASIL DAN PEMBAHASAN}

\section{Analisis Kinerja Trayek Angkutan Perkotaan Eksisting}

Cakupan pelayanan trayek merupakan kondisi dimana seluruh warga dapat menggunakan trayek yang ada untuk kebutuhan perjalanannya. Besarnya cakupan pelayanan bergantung pada seberapa jauh orang itu merasa nyaman untuk berjalan kaki menuju trayek yang bersangkutan selanjutnya menggunakan angkutan umum untuk perjalanannya, luas wilayah cakupan angkutan perkotaan menggunakan wilayah Kecamatan Tanah Grogot yang merupakan daerah perkotaan di Kabupaten Paser. Angkutan perkotaan Kabupaten Paser tidak memiliki rute trayek tetap dan teratur namun perhitungan cakupan pelayanan ini didasarkan pada panjang trayek maksimal yang dapat ditempuh. Berikut ini merupakan hasil perhitungan cakupan pelayanan trayek pada kondisi eksisting.

\section{Tabel 1 Cakupan Pelayanan Angkutan Perkotaan Eksisting}

\begin{tabular}{|c|c|c|c|}
\hline Trayek & $\begin{array}{c}\text { Panjang Trayek } \\
(\mathbf{k m})\end{array}$ & $\begin{array}{c}\text { Area Coverage } \\
(\mathbf{k m})\end{array}$ & $\begin{array}{c}\text { Cakupan } \\
\left.\text { Pelayanan } \mathbf{( k m}^{2}\right)\end{array}$ \\
\hline Angkot Tanah Grogot & Maks 20,0 & 0,4 & 16 \\
\hline
\end{tabular}

Sumber: Hasil Analisis

Berdasarkan cakupan pelayanan, dapat diketahui angka banding yang mengukur panjang jalan yang dilalui oleh angkutan perkotaan Kabupaten Paser, dimana tingkat pelayanan angkutan perkotaan di Kabupaten Paser sebesar 4,76\%.

Kepadatan trayek merupakan angka banding yang mengukur panjang jalan yang dilalui pelayanan angkutan umum dengan luas $(\mathrm{Km} 2)$ daerah yang dilayani. 
Tabel 2. Kepadatan Trayek Angkutan Perkotaan

\begin{tabular}{|c|c|c|c|}
\hline Zona & Luas $\left(\mathrm{Km}^{2}\right)$ & $\begin{array}{c}\text { Panjang Jalan Yang } \\
\text { Dilalui Trayek }\end{array}$ & $\begin{array}{c}\text { Kepadatan Trayek } \\
\text { Per Zona }\left(\mathrm{Km} / \mathrm{Km}^{2}\right)\end{array}$ \\
\hline 1 & $9 \quad 28,45$ & 7,80 & 0,27 \\
\hline 2 & $6 \quad 25,25$ & 4,80 & 0,19 \\
\hline 3 & $\begin{array}{ll} & 28,69 \\
8 & \end{array}$ & 2,50 & 0,09 \\
\hline 4 & $6 \quad 25,12$ & 1,10 & 0,04 \\
\hline 5 & $\begin{array}{ll} & 27,68\end{array}$ & 2,20 & 0,08 \\
\hline 6 & $\begin{array}{ll} & 33,38 \\
8 & \end{array}$ & 0,00 & 0,00 \\
\hline 7 & $\begin{array}{ll} & 44,79 \\
4 & \end{array}$ & 13,90 & 0,31 \\
\hline 8 & $6 \quad 43,26$ & 0,00 & 0,00 \\
\hline 9 & $\begin{array}{ll} & 38,19 \\
4 & \end{array}$ & 8,00 & 0,21 \\
\hline 10 & $9 \quad 41,07$ & 0,00 & 0,00 \\
\hline
\end{tabular}

Sumber: Hasil Analisis

Berdasarkan nisbah panjang trayek dapat diketahui angka banding yang mengukur panjang jalan yang dilalui oleh angkutan perkotaan dengan kepadatan trayek tertinggi terdapat pada zona 7 yaitu $0,38 \mathrm{Km} / \mathrm{Km} 2$.

Kepadatan zona tiap trayek merupakan perbandingan antara jumlah penduduk dengan luas wilayah zona yang dilewati trayek angkutan perkotaan. Semakin tinggi tingkat kepadatannya, maka trayek tersebut dapat dikatakan baik karena dapat melayani seluruh zona yang ada sepanjang lintasannya.

Tabel 3. Kepadatan Penduduk Terhadap Trayek Angkutan Perkotaan

\begin{tabular}{|c|c|c|c|}
\hline Zona & Luas $\left(\mathbf{K m}^{2}\right)$ & $\begin{array}{l}\text { Jumlah } \\
\text { Penduduk } \\
\text { (Orang) }\end{array}$ & $\begin{array}{l}\text { Kepadatan } \\
\text { Penduduk } \\
(\text { Orang/Km²) }\end{array}$ \\
\hline 1 & $9 \quad 28,45$ & 7349 & 258,23 \\
\hline 2 & $6 \quad 25,25$ & 8567 & 339,21 \\
\hline
\end{tabular}




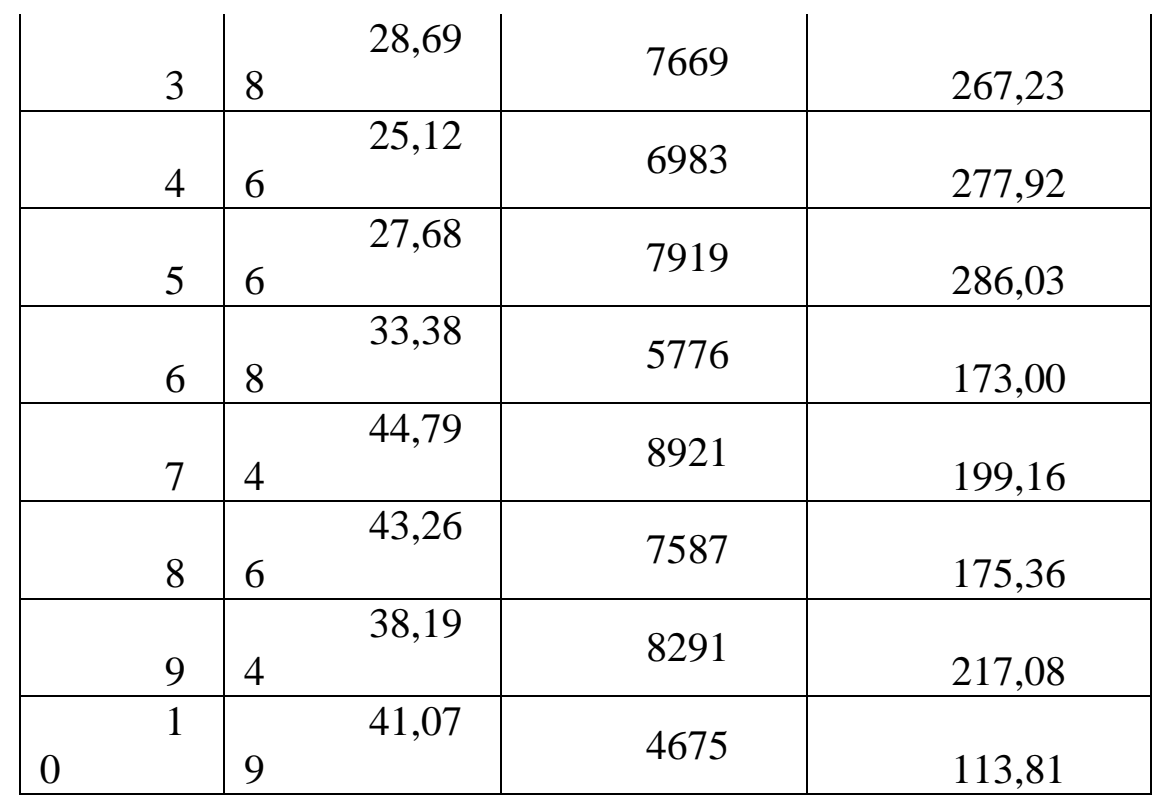

Sumber: Hasil Analisis

Berdasarkan hasil analisa di atas dapat disimpulkan bahwa kepadatan penduduk tertinggi berada pada Zona 2 sebesar 339,21 orang/km2 namun pada perhitungan nisbah trayek sebelumnya kepadatan trayek pada Zona 2 hanya sebesar $0,19 \mathrm{Km} / \mathrm{Km} 2$.

\section{Analisis Jaringan Trayek Usulan}

Pembagian zona yang dilakukan selama penelitian didasari oleh pola tata guna lahan, kemerataan jumlah penduduk, luas wilayah, dan pola jaringan jalan. Di Kabupaten Paser terdapat 24 zona internal dan 14 zona eksternal namun pada kajian studi ini hanya mencakup wilayah perkotaan Kabupaten Paser saja yakni Tanah Grogot. Dengan pembagian zona dijelaskan pada Tabel 4 untuk wilayah Kabupaten Paser di bawah ini.

\section{Tabel 4. Pembagian Zona di Kabupaten Paser}

\begin{tabular}{|r|c|c|c|}
\hline \multicolumn{1}{|c|}{ Zona } & $\begin{array}{c}\text { Nama } \\
\text { Desa/Kelurahan }\end{array}$ & Zona & Nama Desa/Kelurahan \\
\hline 1 & Senaken & 6 & Tanah Periuk, Pepara, Sungai Tuak \\
\hline 2 & Tanah Grogot I & 7 & Tepian Batang, Jone, Tapis \\
\hline 3 & Tanah Grogot II & 8 & Rantau Panjang, Padang Pengrapat, Pulau Rantau \\
\hline 4 & Tanah Grogot III & 9 & Janju, Sempulang \\
\hline 5 & Tanah Grogot IV & 10 & Muara Pasir, Parepat, Sungai Langir \\
\hline
\end{tabular}

\section{Sumber: Hasil Analisis}

Pemilihan moda untuk mengubah matriks asal tujuan perjalanan menjadi matrik asal tujuan perjalanan menggunakan angkutan umum. Dalam tahapan ini dilakukan pemilihan moda menurut jenis moda yang digunakan, dalam identifikasinya dibagi menjadi sepeda, sepeda motor, mobil, angkutan umum, jalan kaki, dan ojek. Berdasarkan pengolahan data dari survei home interview di 
Kabupaten Paser didapatkan proporsi/persentase penggunaan moda dengan gambar V.2 di bawah ini.

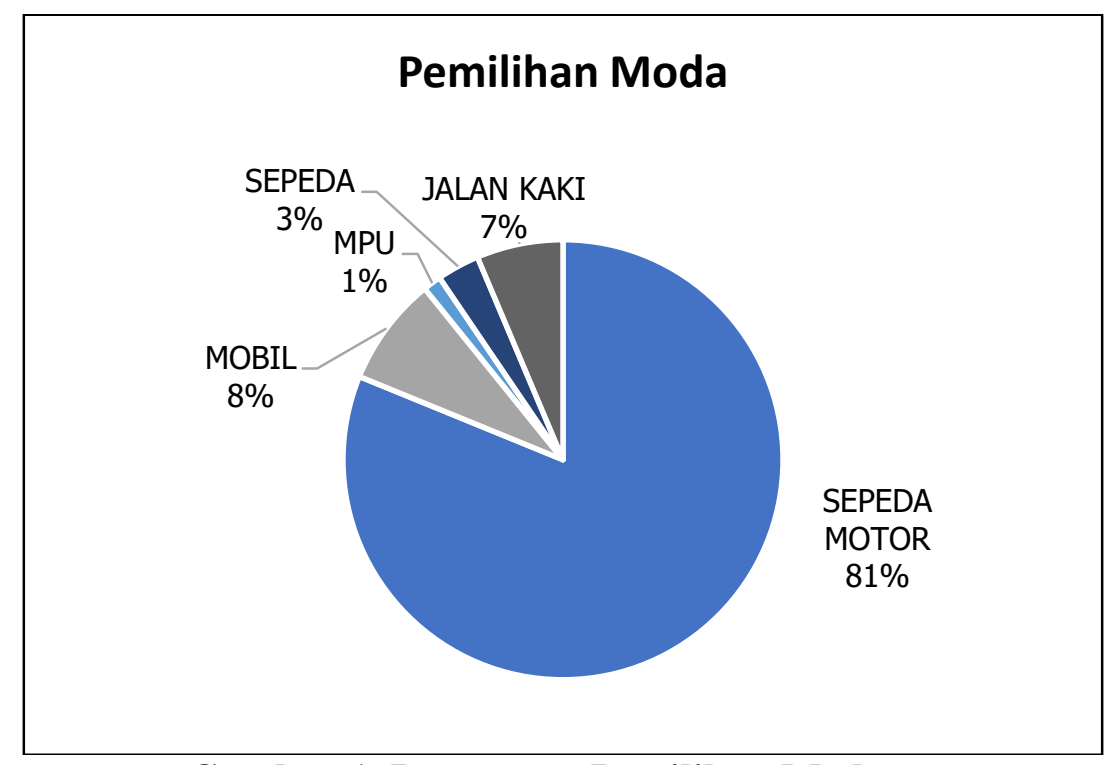

Gambar 1. Persentase Pemilihan Moda

Berdasarkan data di atas, moda yang paling banyak digunakan untuk melakukan perjalanan adalah sepeda motor sebesar $81 \%$ sedangkan proporsi pemilihan moda dengan MPU adalah $1 \%$. Dari gambar 1. diketahui persentase penggunaan angkutan umum sebesar $1 \%$ maka dibuat matriks asal tujuan perjalanan dengan menggunakan angkutan umum, seperti pada Tabel 5. di bawah ini.

Tabel 5. Matrik Asal Tujuan Perjalanan Pengguna Angkutan Umum (Demand Actual) (Trip/Hari)

\begin{tabular}{|c|c|c|c|c|c|c|c|c|c|c|c|}
\hline ZONA & $\mathbf{1}$ & $\mathbf{2}$ & $\mathbf{3}$ & $\mathbf{4}$ & $\mathbf{5}$ & $\mathbf{6}$ & $\mathbf{7}$ & $\mathbf{8}$ & $\mathbf{9}$ & $\mathbf{1 0}$ & $\begin{array}{c}\text { TOTA } \\
\text { L }\end{array}$ \\
\hline $\mathbf{1}$ & 12 & 28 & 18 & 28 & 27 & 7 & 29 & 16 & 30 & 21 & 217 \\
\hline $\mathbf{2}$ & 29 & 9 & 15 & 10 & 12 & 16 & 10 & 10 & 23 & 10 & 146 \\
\hline $\mathbf{3}$ & 18 & 14 & 4 & 5 & 18 & 1 & 5 & 11 & 16 & 7 & 100 \\
\hline $\mathbf{4}$ & 28 & 10 & 4 & 2 & 9 & 1 & 14 & 7 & 25 & 1 & 104 \\
\hline $\mathbf{5}$ & 27 & 11 & 19 & 10 & 7 & 9 & 14 & 15 & 26 & 7 & 145 \\
\hline $\mathbf{6}$ & 6 & 14 & 1 & 3 & 9 & 7 & 17 & 13 & 22 & 12 & 103 \\
\hline $\mathbf{7}$ & 15 & 13 & 5 & 9 & 16 & 16 & 6 & 10 & 26 & 10 & 127 \\
\hline $\mathbf{8}$ & 17 & 10 & 11 & 7 & 15 & 13 & 11 & 5 & 16 & 6 & 112 \\
\hline $\mathbf{9}$ & 31 & 26 & 30 & 25 & 24 & 21 & 17 & 16 & 7 & 14 & 212 \\
\hline $\mathbf{1 0}$ & 23 & 13 & 7 & 3 & 8 & 11 & 10 & 6 & 16 & 3 & 99 \\
\hline $\begin{array}{c}\text { TOTA } \\
\text { L }\end{array}$ & 205 & 148 & 116 & 104 & 145 & 103 & 132 & 112 & 205 & 92 & 1365 \\
\hline
\end{tabular}

Sumber: Hasil analisis.

Dapat diketahui tingkat perpindahan penumpang terbesar terdapat pada zona 1 dengan tata guna lahan berupa pasar dan pertokoan. Angkutan perkotaan Kabupaten Paser dari zona 1 sampai 
zona 10 memiliki jumlah permintaan pengguna jasa yang relatif sama besarannya namun pada kondisi sebenarnya tidak melalui keseluruhan zona wilayah perkotaan. Untuk mengetahui persentase keinginan orang berpindah dari pengguna kendaraan pribadi ke angkutan umum maka dilakukan survey state preference dengan pengambilan sampel penduduk Tanah Grogot tiap zonanya.

Dari hasil survey state preference didapat matriks asal tujuan jumlah permintaan potensial (demand potential) diperoleh dari jumlah kemauan orang berpindah ke angkutan perkotaan ditambah jumlah orang yang telah menggunakan angkutan perkotaan.

Tabel 6. Matrik Asal Tujuan Perjalanan Pengguna Angkutan Umum (Demand Potensial) (Trip/Hari)

\begin{tabular}{|c|c|c|c|c|c|c|c|c|c|c|c|}
\hline OD & $\mathbf{1}$ & $\mathbf{2}$ & $\mathbf{3}$ & $\mathbf{4}$ & $\mathbf{5}$ & $\mathbf{6}$ & $\mathbf{7}$ & $\mathbf{8}$ & $\mathbf{9}$ & $\mathbf{1 0}$ & $\begin{array}{c}\text { TOTA } \\
\mathbf{L}\end{array}$ \\
\hline $\mathbf{1}$ & 135 & 328 & 210 & 332 & 319 & 87 & 341 & 188 & 347 & 245 & 2.531 \\
\hline $\mathbf{2}$ & 371 & 111 & 197 & 135 & 154 & 212 & 130 & 135 & 296 & 130 & 1.871 \\
\hline $\mathbf{3}$ & 375 & 295 & 96 & 104 & 383 & 24 & 104 & 239 & 339 & 160 & 2.119 \\
\hline $\mathbf{4}$ & 495 & 182 & 78 & 39 & 156 & 26 & 241 & 130 & 436 & 26 & 1.810 \\
\hline $\mathbf{5}$ & 371 & 150 & 258 & 139 & 93 & 124 & 191 & 211 & 353 & 98 & 1.988 \\
\hline $\mathbf{6}$ & 67 & 171 & 9 & 36 & 112 & 81 & 202 & 162 & 261 & 139 & 1.241 \\
\hline $\mathbf{7}$ & 210 & 182 & 73 & 130 & 218 & 223 & 83 & 145 & 355 & 135 & 1.754 \\
\hline $\mathbf{8}$ & 281 & 159 & 183 & 122 & 244 & 207 & 177 & 85 & 262 & 98 & 1.818 \\
\hline $\mathbf{9}$ & 324 & 280 & 322 & 267 & 257 & 223 & 179 & 175 & 72 & 153 & 2.251 \\
\hline $\mathbf{1 0}$ & 331 & 182 & 101 & 37 & 112 & 160 & 139 & 85 & 222 & 43 & 1.413 \\
\hline $\begin{array}{c}\text { TOTA } \\
\mathbf{L}\end{array}$ & 2.96 & 2.03 & 1.52 & 1.341 & 2.04 & 1.36 & 1.78 & 1.557 & 2.94 & 1.22 & $\mathbf{1 8 . 7 9 6}$ \\
\hline
\end{tabular}

Sumber : Hasil Analisis

Usulan Trayek Angkutan Perkotaan di Kabupaten Paser:

a. Trayek A

Rute usulan angkutan kota trayek A yaitu Jl.Yos Sudarso - Jl.Untung Suropati - Jl.Pelopor - Jl.Ahmad Yani/Jl.Kuaro. Bentuk rute trayek A adalah linier dengan panjang lintasan trayek 9,7 km. Trayek A melewati 5 (lima) zona internal yaitu zona 1, 2, 3, 5, dan 7 dengan jumlah permintaan penumpang 5376 perjalanan/hari. Jenis kendaraan yang digunakan adalah jenis mobil penumpang umum (MPU) kapasitas 8 orang, dengan asumsi kecepatan rencana $40 \mathrm{~km} / \mathrm{jam}$ maka dapat diketahui waktu perjalanan/travel time (TT) 14,55 menit, waktu perjalanan bolak-balik 33,5 menit

Tabel 7. Matrik O/D Tayek A Usulan

\begin{tabular}{|c|c|c|c|c|c|c|}
\hline Zona & $\mathbf{1}$ & $\mathbf{2}$ & $\mathbf{3}$ & $\mathbf{5}$ & $\mathbf{7}$ & Jumlah \\
\hline $\mathbf{1}$ & 135 & 328 & 210 & 319 & 341 & 1.332 \\
\hline $\mathbf{2}$ & 371 & 111 & 197 & 154 & 130 & 963 \\
\hline $\mathbf{3}$ & 375 & 295 & 96 & 383 & 104 & 1.253 \\
\hline $\mathbf{5}$ & 371 & 150 & 258 & 93 & 191 & 1.062 \\
\hline
\end{tabular}




\begin{tabular}{|c|c|c|c|c|c|c|}
$\mathbf{7}$ & 210 & 182 & 73 & 218 & 83 & 765 \\
\hline Jumlah & 1.463 & 1.065 & 833 & 1.167 & 848 & $\mathbf{5 . 3 7 6}$ \\
\hline
\end{tabular}

Sumber : Hasil Analisis

b. Trayek B

Rute usulan angkutan kota trayek B yaitu Jl.Yos Sudarso - Jl.MT Hariono - Jl.Ahmad Yani - Jl.Kandilo Bahri - Jl.Cendrawasih - J1.Imam Bonjol - Jl.Suprapto - Jl.Ahmad Dahlan - J1.Kusuma Bangsa. Bentuk rute trayek B adalah linear dengan panjang lintasan trayek 23,5 km. Trayek B ini melewati 5 zona internal yaitu zona 1, 6, 7, 8, dan 10 dengan jumlah permintaan penumpang 4293 perjalanan/hari. Jenis kendaraan yang digunakan adalah mobil penumpang umum (MPU) kapasitas 8 orang, dengan asumsi kecepatan rencana $40 \mathrm{~km} / \mathrm{jam}$ maka dapat diketahui waktu perjalanan/travel time (TT) 35,3 menit dan waktu perjalanan bolak - balik 81,1 menit.

\section{Tabel 8. Matrik O/D Tayek B Usulan}

\begin{tabular}{|c|c|c|c|c|c|c|}
\hline Zona & $\mathbf{1}$ & $\mathbf{6}$ & $\mathbf{7}$ & $\mathbf{8}$ & $\mathbf{1 0}$ & Jumlah \\
\hline $\mathbf{1}$ & 135 & 87 & 341 & 188 & 245 & 996 \\
\hline $\mathbf{6}$ & 67 & 81 & 202 & 162 & 139 & 652 \\
\hline $\mathbf{7}$ & 210 & 223 & 83 & 145 & 135 & 797 \\
\hline $\mathbf{8}$ & 281 & 207 & 177 & 85 & 98 & 848 \\
\hline $\mathbf{1 0}$ & 331 & 218 & 145 & 223 & 83 & 1.001 \\
\hline Jumlah & 1.025 & 817 & 948 & 804 & 700 & $\mathbf{4 . 2 9 3}$ \\
\hline
\end{tabular}

Sumber : Hasil Analisis

c. Trayek C

Rute usulan angkutan kota trayek C yaitu Jl.Kandilo Bahri - Jl.Sultan Hasanuddin Jl.Sultan Iskandar Muda - J1.Ahmad Yani/Jl.Noto Sunardi - Jl.Ahmad Yani/Jl.Kuaro. Bentuk rute trayek $\mathrm{C}$ adalah linear dengan panjang lintasan trayek $14 \mathrm{~km}$. Trayek C ini melewati 4 (empat) zona internal yaitu zona 1, 5, 7, dan 9 dengan jumlah permintaan penumpang 3829 perjalanan/hari. Jenis kendaraan yang digunakan adalah mobil penumpang umum (MPU) kapasitas 8 orang, dengan asumsi kecepatan rencana $40 \mathrm{~km} / \mathrm{jam}$ maka dapat diketahui waktu perjalanan/ Travel Time (TT) 21,0 menit dan waktu perjalanan bolak - balik 48,3 menit.

Tabel 9. Matrik O/D Tayek C Usulan

\begin{tabular}{|c|c|c|c|c|c|}
\hline Zona & $\mathbf{1}$ & $\mathbf{4}$ & $\mathbf{7}$ & $\mathbf{9}$ & Jumlah \\
\hline $\mathbf{1}$ & 135 & 332 & 341 & 347 & 1.155 \\
\hline $\mathbf{4}$ & 371 & 139 & 191 & 353 & 1.054 \\
\hline $\mathbf{7}$ & 210 & 130 & 83 & 355 & 778 \\
\hline $\mathbf{9}$ & 324 & 267 & 179 & 72 & 841 \\
\hline Jumlah & 1.041 & 867 & 793 & 1.127 & $\mathbf{3 . 8 2 9}$ \\
\hline
\end{tabular}

Sumber : Hasil Analisis 
Berdasarkan penelitian kinerja jaringan trayek, pola pergerakan matrik asal tujuan, dan tata guna lahan didapatkan 3 jaringan trayek usulan angkutan perkotaan Kabupaten Paser dengan mempertimbangkan :

a. Jaringan trayek angkutan perkotaan yang baru didesain dengan menghubungkan zona zona yang memiliki permintaan perjalanan terbesar.

b. Membuat tingkat tumpang tindih trayek serendah mungkin.

c. Menambah daerah pelayanan, sehingga cakupan pelayanan meningkat dan trayek dapat melayani Kabupaten Paser dengan melakukan penetapan rute sehingga lebih efektif dan efisien.

Berikut merupakan daftar rute angkutan perkotaan usulan :

Tabel 10. Rute Angkutan Perkotaan Usulan Kabupaten Paser

\begin{tabular}{|c|c|c|c|}
\hline No & Trayek & Rute & Jarak (km) \\
\hline 1 & A & $\begin{array}{c}\text { Jl. Yos Sudarso - Jl. Untung Suropati - } \\
\text { Jl. Pelopor - Jl. Ahmad Yani/Jl. Kuaro }\end{array}$ & 9,7 \\
\hline 2 & B & $\begin{array}{c}\text { Jl. Yos Sudarso - Jl. MT Hariono - Jl. } \\
\text { Ahmad Yani - Jl. Kandilo Bahri - Jl. } \\
\text { Cendrawasih - Jl.Imam Bonjol - Jl. } \\
\text { Suprapto - Jl. Ahmad Dahlan - } \\
\text { Jl.Kusuma Bangsa }\end{array}$ & 23,5 \\
\hline 3 & C & $\begin{array}{c}\text { Jl. Kandilo Bahri - Jl. Sultan } \\
\text { Hasanuddin - Jl. Sultan Iskandar Muda } \\
\text { - Jl. Ahmad Yani/Jl.Noto Sunardi - Jl. } \\
\text { Ahmad Yani/Jl.Kuaro }\end{array}$ & 14 \\
\hline
\end{tabular}

Sumber: Hasil Analisis

Kriteria pemilihan rute yang digunakan adalah :

a. Rute yang menghubungkan zona - zona yang memiliki permintaan perjalanan yang tinggi.

b. Melewati pusat kegiatan yang ada di dalam zona sehingga permintaan penumpang pada setiap zona dapat terpenuhi.

c. Jalan yang memiliki lebar lajur dan jalur yang cukup untuk dilalui oleh kendaraan mobil penumpang umum kapasitas 8 penumpang.

d. Pemilihan rute awal dan akhir pada terminal agar memudahkan pengoperasiannya namun pemilihan jalan yang dilalui berbeda.

\section{Perbandingan Kinerja Angkutan Perkotaan Eksisting dengan Hasil Penataan}

Kinerja pelayanan trayek usulan dapat dibandingkan dengan trayek eksisting dengan beberapa indikator. Dari hasil analisis, trayek eksisting diperbaharui menjadi tiga trayek. Hal ini memudahkan masyarakat menggunakan angkutan karena beberapa ruas jalan sudah terlayani angkutan perkotaan. Berikut merupakan perbandingan kinerja trayek eksisting dan trayek usulan. 


\section{Tabel V.35. Perbandingan Kinerja Trayek Eksisting dengan Trayek Usulan}

\begin{tabular}{|c|l|c|c|c|c|c|}
\hline \multirow{2}{*}{ No } & \multirow{2}{*}{ Indikator } & \multirow{2}{*}{ Satuan } & \multirow{2}{*}{ Eksisting } & \multicolumn{3}{|c|}{ Usulan } \\
\cline { 5 - 7 } & & & & Trayek A & Trayek B & Trayek C \\
\hline 1 & Jumlah Armada & armada & 15 & 22 & 44 & 23 \\
\hline 2 & Frekuensi Rata-Rata & kend/jam & 2 & 39 & 32 & 29 \\
\hline 3 & Headway Rata-Rata & menit & 30 & 1,56 & 1,88 & 2,11 \\
\hline 4 & $\begin{array}{l}\text { Waktu Tempuh Rata- } \\
\text { Rata }\end{array}$ & menit & & 14,55 & 35,25 & 21,00 \\
\hline 5 & Cakupan Pelayanan & $\%$ & $5 \%$ & $11 \%$ & $11 \%$ & $11 \%$ \\
\hline 6 & Faktor Muat Rata-Rata & $\%$ & $30 \%$ & $70 \%$ & $70 \%$ & $70 \%$ \\
\hline 7 & $\begin{array}{l}\text { Tingkat Tumpang Tindih } \\
\text { Rata-Rata }\end{array}$ & $\%$ & $0 \%$ & $12 \%$ & $3 \%$ & $4 \%$ \\
\hline 8 & Tarif & Rupiah & Rp10.000 & Rp 4.000 & Rp 8.000 & Rp 7.000 \\
\hline
\end{tabular}

Sumber : Hasil Analisis

Jumlah yang dibutuhkan oleh trayek usulan adalah 89 armada, maka diperlukan penambahan armada karena jumlah armada pada trayek eksisting yang beroperasi hanya sebesar 15 armada. Dengan penambahan jumlah trayek dan merasionalkan jumlah armada, kinerja pelayanan dapat diperbaiki. Frekuensi angkutan umum eksisting rata-rata sebesar $2 \mathrm{kend} / \mathrm{jam}$ dapat diperbaiki menjadi $34 \mathrm{kend} / \mathrm{jam}$. Waktu antar kendaraan juga dapat ditingkatkan dari kondisi eksisting sebesar 30 menit menjadi 1,85 menit, dan waktu perjalanan rata-rata eksisting yang belum dapat ditentukan karena tidak ada penetapan asal dan tujuan menjadi 23,6 menit. Tarif yang akan dibayarkan pengguna jasa pada trayek usulan telah dan disesuaikan dengan jarak tempuh, maka diharapkan dari pengguna maupun penyedia jasa angkutan perkotaan tidak mengalami kerugian.

\section{KESIMPULAN}

Kinerja trayek eksisting belum memenuhi standar yang telah ditetapkan, beberapa indikator bahkan tidak bisa dilakukan penilaian karena belum ada asal dan tujuan yang tetap. Hasil dari penataan, diperoleh angkutan perkotaan yang semula satu trayek menjadi tiga trayek sebagai berikut :trayek A Melalui ruas Jl.Yos Sudarso - Jl.Untung Suropati - Jl.Pelopor - J1.Ahmad Yani/Jl.Kuaro dengan panjang trayek 9,7 km. Dengan jumlah armada sebanyak 22 armada, frekuensi 39 kend/jam, headway 1,56 menit, dan waktu tempuh 14,55 menit; trayek B melalui ruas Jl.Yos Sudarso - Jl.MT Hariono - Jl. Ahmad Yani - Jl.Kandilo Bahri - Jl.Cendrawasih - Jl.Imam Bonjol - Jl.Suprapto - Jl.Ahmad Dahlan - Jl.Kusuma dengan panjang trayek 23,5 km. Dengan jumlah armada sebanyak 44 armada, frekuensi $32 \mathrm{kend} / \mathrm{jam}$, headway 1,88 menit, dan waktu tempuh 35,25 menit. Trayek C, melalui ruas Jl. Kandilo Bahri - Jl. Sultan Hasanuddin - Jl. Sultan Iskandar Muda - Jl. Ahmad Yani/Jl.Noto Sunardi - Jl. Ahmad Yani/Jl.Kuaro. Dengan panjang trayek $14 \mathrm{~km}$. Dengan jumlah armada sebanyak 23 armada, frekuensi $29 \mathrm{kend} / \mathrm{jam}$, headway 2,11 menit, dan waktu tempuh 21 menit.

Perbandingan trayek eksisting dan trayek usulan dapat diketahui dari beberpa indikator, jumlah armada pada trayek eksisting hanya 15 armada dan pada trayek usulan sebanyak 89 armada, frekuensi angkutan umum eksisting rata-rata sebesar 2 kendaraan/jam dapat diperbaiki menjadi 34 
kendaraan/jam. Waktu antar kendaraan juga dapat ditingkatkan dari kondisi eksisting sebesar 30 menit menjadi 1,85 menit pada trayek usulan, dan waktu perjalanan rata-rata eksisting yang belum dapat ditentukan karena tidak ada penetapan asal dan tujuan menjadi 23,6 menit. Tarif yang akan dibayarkan pengguna jasa pada trayek usulan telah diperhitungkan dan disesuaikan dengan jarak tempuh, maka diharapkan dari pengguna maupun penyedia jasa angkutan perkotaan tidak mengalami kerugian.

\section{REFERENSI}

1. Giannopoulus, G. A.1989, Bus Planning and Operation In Urban Areas, A Practical Guide, Avebury, Gower Publishing Company Ltd, England.

2. Tamin, Ofyar Z, 2000, Perencanaan dan Permodelan Transportasi, Edisi kedua, Institut Teknologi Bandung, Bandung.

3. Undang-Undang Nomor 22 Tahun 2009 Tentang Lalu Lintas dan Angkutan Jalan, Direktorat Jenderal Perhubungan Darat, Jakarta

4. Keputusan Menteri Nomor 89 Tahun 2002 Tentang Penetapan Tarif dan Formula Perhitungan Biaya Pokok Angkutan Penumpang dengan Mobil Bus Umum Antar Kota Kelas Ekonomi, Direktorat Jenderal Perhubungan Darat, Jakarta.

5. Peraturan Pemerintah Nomor 74 Tahun 2014 Tentang Angkutan Jalan, Direktorat Jenderal Perhubungan Darat, Jakarta.

6. Peraturan Menteri Nomor 98 Tahun 2013 Tentang Standar Pelayanan Minimal Angkutan Orang dengan Kendaraan Bermotor Umum dalam Trayek, Direktorat Jenderal Perhubungan Darat, Jakarta.

7. Peraturan menteri nomor 111 tahun 2015 tentang tata cara penetapan batas kecepatan, Direktorat Jenderal Perhubungan Darat, jakarta.

8. SK Dirjen No 687 Tahun 2002 Tentang Pedoman Teknis Penyelenggaraan Angkutan Penumpang Umum Di Wilayah Perkotaan dalam Trayek Tetap dan Teratur, Direktorat Jenderal Perhubungan Darat, Jakarta.

9. Kelompok PKL Kabupaten Paser . (2018). Pola Umum Lalu Lintas Angkutan Jalan Kabupaten Paser, Bekasi.

10. Fauzi, S. (2009). Penataan Rute Trayek Angkutan Perkotaan Kabupaten Ponorogo. Bekasi: Sekolah Tinggi Transpotasi Darat.

11. Kuntara, A. (2013). Penataan Rute Trayek Angkutan Perkotaan Kabupaten Banyuwangi. Bekasi: Sekolah Tinggi Transportasi Darat. 